\title{
Exterior Sourcing and Technology Distinctness as Indicators for Radical Innovations: Evidence from Patents in Information Technology Industry
}

\author{
Avimanyu Datta \\ MQM Department, College of Business, Illinois State University, Normal, USA \\ E-mail:avimanyu.datta@gmail.com,adatta@ilstu.edu \\ Received May 16, 2011; revised July 23, 2011; accepted July 30, 2011
}

\begin{abstract}
We hypothesized and tested the role of looking beyond a firm's focal industry on technology distinctness and both of their impacts on radicalness of innovations. We used patent filings from 1996 through $2009(N=$ 192,070) from the IT industry within the S \& P-500 database. We also classified exterior sourcing as high and low, and divided technology distinctness as high, medium, and low. We found that when innovations are primarily sourced exteriorly, there is a negative relationship with technology distinctness. We also found that the relationship between technology distinctness and radicalness is stronger at lower levels of exterior sourcing than at higher levels. Further, when exterior sourcing is unable to create highly distinct technologies, the relationship between technology distinctness and radicalness goes from sparsely significant to significantly negative.
\end{abstract}

Keywords: Radical Innovations, Exterior Sourcing, Absorptive Capacity, Technology Distinctness

\section{Introduction}

Failure to capture emerging markets is the root cause of failure of large incumbent firms [1-5]. Emerging markets are captured by successfully introducing radical innovations [6-11].

Radical inventions show key characteristics that are inherently different from existing products or technologies (Burgelman, et al., 2006). Radicalness is a function of newness and differentness. Specifically, it has three characteristics: novel, unique, and has an impact on future technology [11]. Successful radical inventions provide the opportunity for the innovating firm in gaining a sustainable competitive advantage and for the subsequent generation of economic rents [12,13]. A firm becomes long-lived when it can come up with radical new products without hampering the existing markets [14-16]. The literature has shown that not all firms are good at coming up with radical innovations, as they are unable to come out of their core rigidities $[17,18]$. Thus, it of theoretical and practical interest to expand on our knowledge on the antecedents of radical innovations.

The ability to introduce radical innovations to market is necessitated by a firm's ability to create or source radical innovations. Technologically rich firms often go beyond its own focal industry for opportunities of diversifying knowledge related to new technologies and innovations [19-21]. Integration of complementary technologies produce unique combinations through experimentation [22] and increases the explorative ability of the firm beyond its current technology stock, resulting in novel innovations. By looking for innovations outside its own industry, a firm increases the number and variety of possible combinations and potential for high novel solutions $[23,24]$. In other words, firms need to extend their boundaries to tap innovations outside its focal industry to be able to acquire complementary technologies which in turn contribute to radical innovations. Despite the rewards from going outside one's focal industry, there are considerable penalties a firm needs to pay, in terms of integration costs [25] and information overload [26,27], leading to inconclusive results [28] and high cost of recombinatory innovation $[24,29]$.

In this study we investigate how exterior sourcing and technology distinctness affect radicalness of innovations. Thus, the key research question is: how exterior sourcing and technology distinctness affect radicalness of innovations? 


\section{Theory and Hypotheses}

Ahuja and Lampert (2001) define radical or breakthrough innovations as "those foundational innovations that serve as the basis for many subsequent technical developments" [28]. Dahlin and Behrens (2005) consider technologies to be radical when they are: (a) novel, (b) unique, and (c) have an impact on future technology. In order to be labeled as radical invention, new knowledge, or the recombination of already existing knowledge must be unique [11].

\subsection{Exterior Sourcing and Technological Distinctness}

Sorensen and Stuart (2000) observed that as firms grow and age, they start citing their own patents in their quest to seek future innovations. Therefore with age and size firms tend to look more inward towards its innovative approaches [30]. Sources of such innovations are either within a firm's boundaries or within its focal industries. Such existing synergies generate innovations that exploit exiting competencies [30], resulting in incremental innovations, through exchange and combination of existing knowledge. Thus, alliances and networks within the same industry and similar technologies enhance innovation incrementally. Such alliances often create technology redundancies that diminish the opportunities to create radical innovations.

Conversely, we argue diversification in terms of tapping innovations outside the firm's focal industry (exterior) and distinctness of technology may lead to radicalness of innovations. Complementarities of technology facilitate exploration through experimentation with new competencies [22,31]. Technology complementarities between firms enhance the firm's ability to create radical innovations [32] by enhancing the novelty of innovations [33-35]. In other words, firms need to extend their boundaries and tap innovations outside their own focal industry to be able to acquire complementary technologies, which in turn contribute to radical innovations.

\subsection{Research Hypotheses}

Exterior sourcing, increases the number and variety of possible combinations and potential for high novel solutions $[23,24]$. It also provide firms with access to diverse problem-solving heuristics [24], which can increase the exploratory content of new combinations of knowledge [36] that in turn leads to radical innovations. This leads us to ask an important question linking sources and types of innovation, "whether firms need to extend their boundaries to source innovation outside their current technol- ogy class in order to increase the chance that they will find or develop radical innovations?" Despite its rewards, integrating complementary technology and extension of boundaries beyond the focal industry results in high integration costs [25] and requires significant effort [37]. As the technological distance through exterior sourcing increases a firms relative absorptive capacity declines $[24,38]$, which increases the cost of recombinatory innovation $[24,29]$.

When innovations come from various exterior sources, a firm may be plagued with high information overload, which gets in their way especially when the technology is drastically distinct from its current portfolio. However, the information overload may not get in its way if the technology is moderately or austerely distinct from its own portfolio. Thus, when a firm has too many sources of innovations outside its focal industry, high technology distinctness makes the firms solve a dual problem: information overload, and getting a grasp on newer technology. At medium or lower technology distinctness, the problem is principally related to managing information overload. Similarly, when a minor percentage of innovations come outside the industry, the chance that that technology will be highly distinctive is nominal. Lower exterior sourcing can therefore invite innovations that are moderately or modestly distinct from a firm's current portfolio. Whether an innovation is majorly or trivially sourced from exterior sources, at lower degree of technology distinctness, the relation to radicalness will be trivial or even negative. The reason is when contacts outside a focal industry cannot create distinct technologies to explore, the cost of keeping it exceeds the benefits, and resultant radicalness that often results in successful experimentation with distinct technologies and its combinations, will not materialize. Taken together, we formally state:

Hypothesis 1: Exterior sourcing will lead to technology distinctness in innovation, and the relationship will be negative at high levels of technology distinctness and positive at marginal or modest levels of technology distinctness.

Hypothesis 2: Exterior sourcing and technology distinctness lead to radicalness of innovation, such that high levels of technological distinctness will account for maximum variance toward radicalness. At marginal or modest levels of distinctness, there will a negative relationship with radicalness.

\section{Method}

\subsection{Industry Selection, Data Collection Sampling Strategy}

We collected data from the information technology (IT) 
industry. Our data is analyzed at the patent level. Patents have long been considered proxies for innovative outputs of organizations [11,39-43]. We selected our firms from Standard \& Poor's (S \& P)-500 American companies covering about $75 \%$ of the American equity market by capitalization. From that list we shortlisted 81 firms listed in the information technology (IT) industry. We collected patents from 1996-2009 for all 81 firms from the USPTO (United States Patent and Trademark Office) patent database.

\subsection{Independent Variables: Innovations Sources Outside Focal Industry (Exterior Sources)}

We looked at backward citations (i.e., citations of prior patents within the patent application as sources of innovation). Arithmetically, for each patent of each firm, if all the backward citations are denoted by $B$, all the citations from partners are denoted by $P$, and all the self-citations are denoted by $S$, then the Exterior sourcing Citations, $\mathrm{EC}=B-(S+P)$. To create a scale (values ranging from 0 through 1), we divided Exterior sourcing Citation (EC) by the total number of backward citations $(B)$, and called Exterior sourcing Sources,

$$
E=\frac{B-(S+P)}{\boldsymbol{B}} \text {. }
$$

\subsection{Independent Variables: Technology Distinctness}

We defined technological distinctness as a measure of diversification of the technology of focus within the patent application vis-à-vis the applying firm's own core

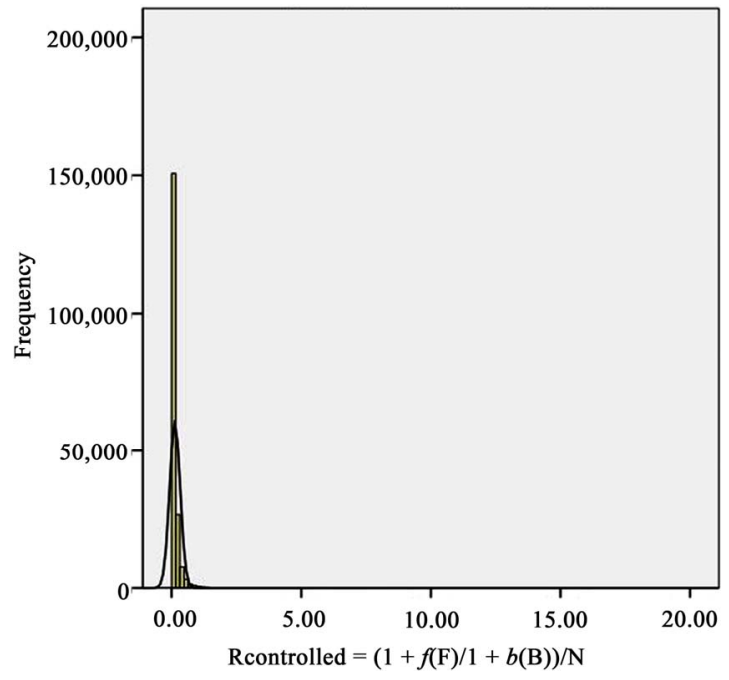

(a) competence. From the standpoint of patents, it meant that we first looked at the "technology class match," which is a percentage that shows how similar a technology is to a firm's previous cited works, and then subtracted the technology class match from 1 to compute technology distinctness. Thus, Technology Distinctness $(D)$ is $1-\operatorname{prob}\left(C_{x i}\right) \cap \operatorname{prob}\left(C_{y j}\right)$, where $x$ is the focal patent and $y$ is patent that $x$ has cited and has a technology overlap.

\subsection{Dependent Variable: Radicalness}

Radicalness for each patent by each firm is calculated by $R=(1+(f) F) /(1+(b) B)$, where $F=$ Forward citation and $f=$ forward class match; $B=$ Backward citation and $b=$ backward class match. Also, older patents receive more forward citations than newer patents, making them look artificially more radical than in reality. To account for this we divided $\mathrm{R}$ by the number of years have passed since the patent was announced (not granted) from the last date of our patent search data, which was June 30, 2009. Thus $R_{\text {controlled }}=((1+(f) F) /(1+(b) B)) / N$, where $N=$ is the integral value of number of years lapsed from the date of patent announced through June 30, 2009. In Figure 1(a), we present the distributional properties of

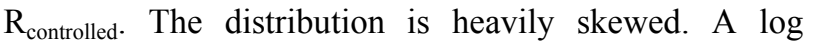
transformation, however, improves the distribution properties, converting it to more of a normal distribution as shown in Figure 1(b). For the purpose of analysis, we will be using the log transformation of $R_{\text {controlled, }}$ i.e.,

$$
\log \left(R_{\text {controlled }}\right)=\log \left(\left(\frac{(1+(f) F) /(1+(b) B)}{N}\right)\right) .
$$

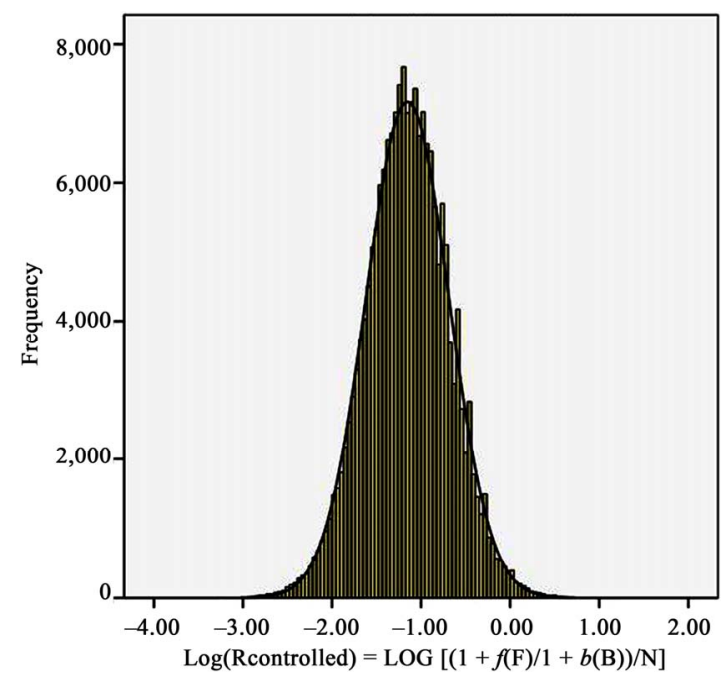

(b)

Figure 1. Distribution of radical scores and radical transformation: (a) Distribution of radical scores, controlled for year; (b) Distribution after log transformation. 


\subsection{Statistical Analysis}

When there are two Independent Variables, A and B causing $\mathrm{C}$, and that $\mathrm{A}$ also causes $\mathrm{B}$, one should regress $\mathrm{B}$ on $\mathrm{A}$ and $\mathrm{C}$ on $\mathrm{A}$ and $\mathrm{B}$ [44]. To see if at higher degree of Exterior sourcing affect a firm's ability to generate radical innovations we broke down exterior sourcing as high $(E>0.5)$ and low $(E \leq 0.5)$. To see how radicalness is affected by degree of Exterior sourcing (high or low) and varying degrees of technology distinctness, we classified technology distinctness into high $(D>0.66)$, medium $(0.33<D \leq 0.66)$, and low $(D \leq 0.33)$. The combination will give us 1 overall and 6 specific equation for hypothesis 1 and same for hypothesis 2 . Thus, we ran fourteen path models.

System of equations formed by regressing Technology Distinctness $(D)$ on Exterior sourcing $(E)$, for testing hypothesis 1:

$$
D=\beta_{0}+\beta E+\mathrm{e}(\text { overall })
$$

(where $D$ is Technology Distinctness, $E$ is Exterior sourcing and, and $\beta$ is path coefficient for $E$ ). The above equation will be broken down into combinations of High and Low values of $D$ and High, Mid and Low Values for E)

$$
D_{h h}=\beta_{0}+\beta_{h h} E_{h}+\mathrm{e}
$$

(where $D_{h h}=D>0.66$ is High Technology Distinctness at high Exterior sourcing i.e. $E_{h}=E>0.5$. $\beta_{h h}$ is Path coefficient for $E_{h}$ )

$$
D_{m h}=\beta_{0}+\beta_{m h} E_{h}+\mathrm{e}
$$

(where $D_{m h}=0.33<D \leq 0.66$ is Medium Technology Distinctness at high Exterior sourcing i.e. $E_{h}=E>0.5$. $\beta_{m h}$ is Path coefficient for $E_{h}$ )

$$
D_{l h}=\beta_{0}+\beta_{l h} E_{h}+\mathrm{e}
$$

(where $D_{m h}=D \leq 0.33$ is Low Technology Distinctness at high Exterior sourcing i.e. $E_{h}=E>0.5$. $\beta_{l h}$ is Path coefficient for $E_{h}$ )

$$
D_{h l}=\beta_{0}+\beta_{h l} E_{l}+\mathrm{e}
$$

(where $D_{h l}=D>0.66$ is High Technology Distinctness at low Exterior sourcing i.e. $E_{h}=E<0.5$. $\beta_{h l}$ is Path coefficient for $E_{l}$ )

$$
D_{m l}=\beta_{0}+\beta_{m l} E_{l}+\mathrm{e}
$$

(where $D_{m l}=0.33<D \leq 0.66$ is Medium Technology Distinctness at low Exterior sourcing i.e. $E_{h}=E<0.5$. $\beta_{l m}$ is Path coefficient for $E_{l}$ )

$$
D_{l l}=\beta_{0}+\beta_{l l} E_{l}+\mathrm{e}
$$

(where $D_{l l}=D \leq 0.33$ is Low Technology Distinctness at low Exterior sourcing i.e. $E_{h}=E<0.5$. $\beta_{l l}$ is Path coeffi- cient for $E_{l}$ )

System of equations formed by regressing Radicalness $(R)$ on Technology Distinctness $(D)$ and Exterior sourcing $(E)$, for testing hypothesis 2 :

$$
R=\beta_{0}+\beta_{1} E+\beta_{2} D+\mathrm{e}(\text { overall })
$$

(where $R$ is Radicalness, $E$ is Exterior sourcing and $D$ is Technology Distinctness, $\beta_{1}$ is path coefficient for $\mathrm{E}$ and $\beta_{2}$ is path coefficient for $D$ ). The above equation will be broken down into combinations of High and Low values of $D$ and High, Mid and Low Values for $E$ to see its impact on Corresponding Radicalness $R$ )

$$
R_{h h}=\beta_{0}+\beta_{1 h h} E_{h}+\beta_{2 h h} D_{h}+\mathrm{e}
$$

(where $R_{h h}$ is Radicalness at high Exterior sourcing i.e. $E_{h}=E>0.5$; high Technology Distinctness i.e., $D_{h}=D>$ 0.66. $\beta_{1 h h}$ and $\beta_{2 h h}$ are path coefficients for $E_{h}$ and $D_{h}$, respectively)

$$
R_{h m}=\beta_{0}+\beta_{1 h m} E_{h}+\beta_{2 h m} D_{m}+\mathrm{e}
$$

(where $R_{h h}$ is Radicalness at high Exterior sourcing i.e. $E_{h}=E>0.5$; Medium Technology Distinctness i.e, $D_{m}=$ $0.33<D \leq 0.66$. $\beta_{1 h m}$ and $\beta_{2 h m}$ are path coefficients for $E_{h}$ and $D_{m}$, respectively)

$$
R_{h l}=\beta_{0}+\beta_{1 h l} E_{h}+\beta_{2 h l} D_{l}+\mathrm{e}
$$

(where $R_{h h}$ is Radicalness at high Exterior sourcing i.e. $E_{h}=E>0.5$; Low Technology Distinctness i.e., $D_{l}=D \leq$ 0.33. $\beta_{1 h l}$ and $\beta_{2 h l}$ are path coefficients for $E_{h}$ and $D_{l}$, respectively)

$$
R_{l h}=\beta_{0}+\beta_{1 l h} E_{l}+\beta_{2 l h} D_{h}+\mathrm{e}
$$

(where $R_{l h}$ is Radicalness at Low Exterior sourcing i.e. $E_{l}$ $=E \leq 0.5$; high Technology Distinctness i.e., $D_{h}=D>$ 0.66. $\beta_{1 l h}$ and $\beta_{2 l h}$ are path coefficients for $E_{l}$ and $D_{h}$, respectively)

$$
R_{l m}=\beta_{0}+\beta_{1 l m} E_{l}+\beta_{2 l m} D_{m}+\mathrm{e}
$$

(where $R_{l h}$ is Radicalness at Low Exterior sourcing i.e. $E_{l}$ $=E \leq 0.5$; medium Technology Distinctness i.e., $D_{m}=$ $0.33<D \leq 0.66$. $\beta_{1 l m}$ and $\beta_{2 l m}$ are path coefficients for $E_{l}$ and $D_{m}$, respectively)

$$
R_{l l}=\beta_{0}+\beta_{1 l l} E_{l}+\beta_{2 l l} D_{l}+\mathrm{e}
$$

(where $R_{l h}$ is Radicalness at Low Exterior sourcing i.e. $E_{l}$ $=E \leq 0.5$; low Technology Distinctness i.e., $D_{l}=0.33<$ $D \leq 0.66$. $\beta_{1 l l}$ and $\beta_{2 l l}$ are path coefficients for $E_{l}$ and $D_{l}$, respectively).

\section{Results}

\subsection{Hypothesis 1}

The findings are depicted in Table 1. Considering the 
entire sample, hypothesis 1 was supported based on the path model for Equation ( 1 ) ( $R 2$ and Adj $R 2=0.001 ; \beta=$ $0.023 ; p<0.001)$. Looking at case-wise analysis, we found that at high exterior sourcing (Equations (1a), (1b), and (1c); $E>0.5), R 2$ improved and $\beta$ transformed from negative to positive as technology distinctness moved from high to medium to low. Specifically, high degree of exterior sourcing, we see a very low variance and a negative $\beta$ in Equation (1a) $(R 2=0.001 ; \operatorname{Adj} R 2=0.001$; $\left.\beta_{h h}=-0.023 ; p<0.001\right)$ at high technology distinctness $(D>0.66)$. This gets improved at medium technology distinctness $\left(R 2=0.009 ; \operatorname{Adj} R 2=0.009 ; \beta_{m h}=0.093 ; p\right.$ $<0.001$; Equation (1b)) and low technology distinctness $\left(R 2=0.008 ; \operatorname{Adj} R 2=0.008 ; \beta_{l h}=0.092 ; p<0.001\right.$; Equation (1c)). At low exterior sourcing (Equations (1d), (1e), and (1f); $E \leq 0.5)$, there is substantial negative variance with high technology distinctness $(R 2=0.394$; $\operatorname{AdjR} 2=0.394 ; \beta_{h l}=-0.628 ; p>0.001 ;$ Equation (1d)), a moderate positive variance with medium technology distinctness $\left(R 2=0.028 ; \operatorname{Adj} R 2=0.028 ; \beta_{m l}=0.167 ; p>\right.$ 0.001 ; Equation (1e)) and slight improvement in the positive variance with low technology distinctness $(R 2=$ $0.042 ; \operatorname{Adj} R 2=0.041 ; \beta_{l l}=0.204 ; \mathrm{p}>0.001$; Equation (1f)). Empirically our declaration of Hypothesis 1 was supported by the path models from Equations (1), (1a), (1b), (1c), (1d), (1e) and (1f).

\subsection{Hypothesis 2}

The findings are depicted in Table 2. Considering the entire sample, hypothesis 2 was supported based on the path model for Equation (2) $\left(R 2=0.09 ; \operatorname{Adj} R 2=0.09 ; \beta_{1}\right.$ $\left.=-0.254 ; \beta_{2}=0.165 ; p<0.001\right)$. Looking at the case wise analysis for combinations high-low exterior sourcing and high-mid-low technology distinctness, as we moved from high to medium to low technology distinctness, we observed: a) variance accounted for $(R 2)$ decreases; b) the beta weights for paths from technology distinctness to radicalness reduces and then becomes negative and c) the beta weights for paths from exterior sourcing to radicalness remains negative but with lesser intensity. This observation remains constant irrespective of whether the innovations came from high degree $(E>$ $0.5)$ low degree $(E \leq 0.5)$ of exterior sourcing. Specifically, when technology distinctness is high $(D>0.66)$, there is a substantial $R 2$ and a positive path coefficient from technology distinctness to radicalness, as explicated through the path model for Equation (2a) for high exterior sourcing $\left(R 2=0.108 ; \operatorname{Adj} R 2=0.108 ; \beta_{1 h h}=-0.193\right.$; $\left.\beta_{2 h h}=0.261 ; p<0.001\right)$, and (2d) for low exterior sourcing $\left(R 2=0.151 ; \operatorname{Adj} R 2=0.150 ; \beta_{11 h}=-0.157 ; \beta_{2 h h}=\right.$ $0.270 ; p<0.001)$. When technology distinctness is me$\operatorname{dium}(0.33<D \leq 0.66)$, there is a reduced $R 2$ and a reduced positive path coefficient from technology distinctness to radicalness, as explicated through the path model for Equation $(2 \mathrm{~b})$ for high exterior sourcing $[R 2=$ $0.024 ; \operatorname{Adj} R 2=0.023 ; \beta_{1 h m}=-0.154(p<0.001) ; \beta_{2 h m}=$ $0.007(p<0.01)]$, and $(2 \mathrm{e})$ for low exterior sourcing $[R 2$ $=0.022 ; \operatorname{Adj} R 2=0.022 ; \beta_{11 m}=-0.150 ; p<0.001 ; \beta_{2 l m}=$ $0.020(p<0.01)]$. When technology distinctness is low $(D \leq 0.33)$, there is a reduced $R 2$ and a negative path coefficient from technology distinctness to radicalness, as explicated through the path model for Equation (2c) for high exterior sourcing $(R 2=0.024$; $\operatorname{Adj} R 2=0.024$; $\left.\beta_{1 h l}=-0.139 ; \beta_{2 h l}=-0.059 ; p<0.001\right)$, and (2f) for low exterior sourcing $\left(R 2=0.032 ; \operatorname{Adj} R 2=0.032 ; \beta_{1 l l}=\right.$ $\left.-0.151 ; \beta_{2 l l}=-0.068 ; p<0.001\right)$. Thus, the path models from Equations (2), (2a), (2b), (2c), (2d), (2e) and (2f) confirms our assertions in hypothesis 2 .

Table 1. Effect of exterior sourcing on technological distinctness (case-wise and overall): hypothesis.

\begin{tabular}{|c|c|c|c|c|c|c|}
\hline \multirow{12}{*}{$\begin{array}{c}\text { Exterior sourcing } \\
\text { (tapping innovations } \\
\text { outside the } \\
\text { focal industry) }\end{array}$} & & \multicolumn{3}{|c|}{ Technological Diversity } & \multirow{12}{*}{$\begin{array}{l}\text { Exterior } \\
\text { Sourcing } \\
\text { (Overall) }\end{array}$} & \multirow{2}{*}{$\begin{array}{c}\text { Technological Diversity } \\
\text { (Overall) }\end{array}$} \\
\hline & & High & Medium & Low & & \\
\hline & \multirow{7}{*}{ High } & Equation (1a) & Equation (1b) & Equation (1c) & & Equation (1) \\
\hline & & $R 2=0.001 * *$ & $R 2=0.009 * *$ & $R 2=0.008^{* *}$ & & $R 2=0.001^{*} *$ \\
\hline & & $\operatorname{Adj} R 2=0.001 * *$ & $\operatorname{Adj} R 2=0.009 * *$ & $\operatorname{Adj} R 2=0.008^{* *}$ & & $\operatorname{Adj} R 2=0.001 * *$ \\
\hline & & $\beta_{h h}=-0.023 * *$ & $\beta_{m h}=0.093 * *$ & $\beta_{\mathrm{l} h}=0.092 * *$ & & $B=0.023 * *$ \\
\hline & & $N=45892$ & $N=108841$ & $N=37660$ & & $N=192070$ \\
\hline & & Equation (1d) & Equation (1e) & Equation (1f) & & \\
\hline & & $R 2=0.394 * *$ & $R 2=0.028 * *$ & $R 2=0.042 * *$ & & \\
\hline & \multirow[t]{3}{*}{ Low } & $\operatorname{Adj} R 2=0.394 * *$ & $\operatorname{Adj} R 2=0.028 * *$ & $\operatorname{Adj} R 2=0.041 * *$ & & Hypothesis 1: Supported \\
\hline & & $\beta_{h l}=-0.628^{* *}$ & $\beta_{m l}=0.167 * *$ & $\beta_{l l}=0.204^{* *}$ & & \\
\hline & & $N=7582$ & $N=16990$ & $N=7715$ & & \\
\hline
\end{tabular}

$*_{i}<0.001$ 
Table 2. Effect of exterior sourcing and technological distinctness on radicalness (case-wise and overall): hypothesis 2.

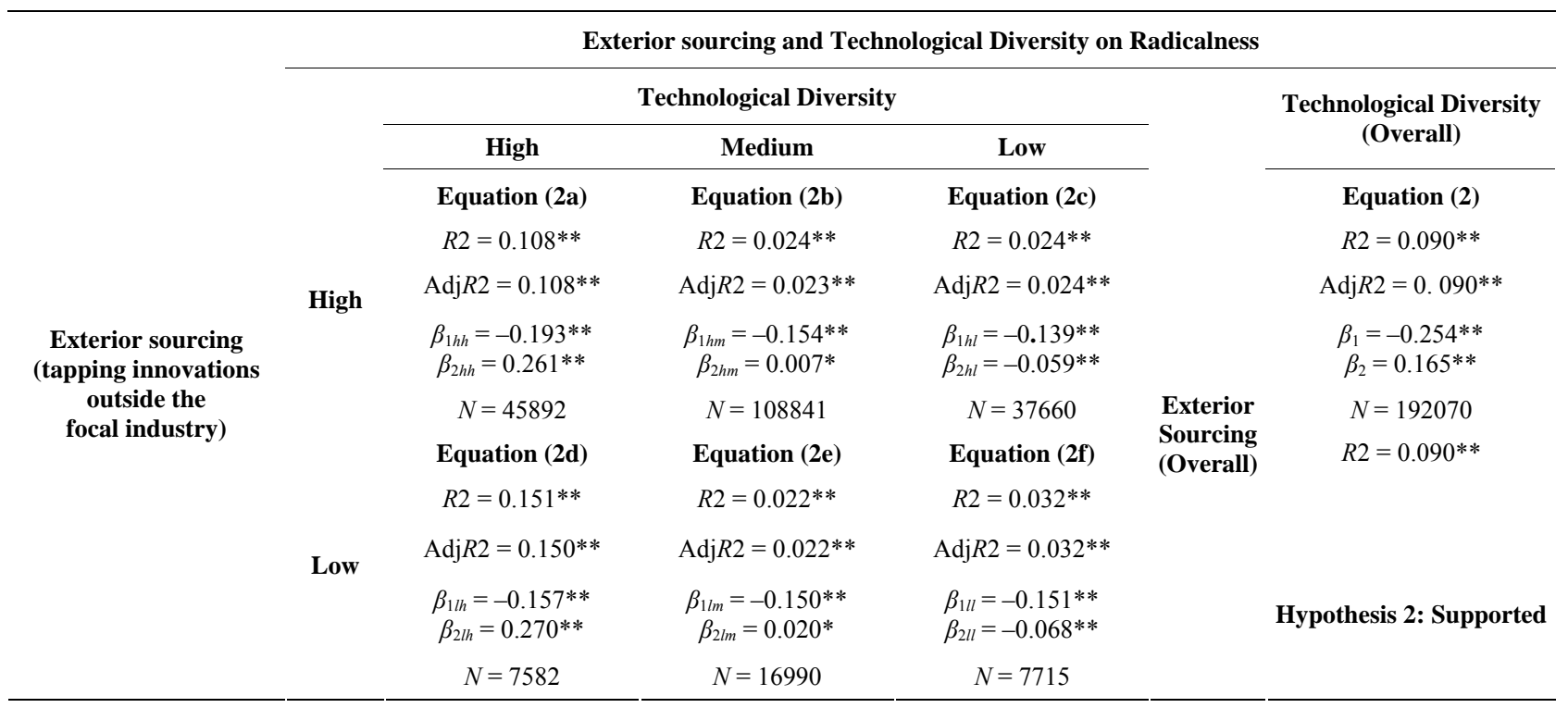

$* * p<0.001 ; * p<0.01 \mathrm{~s}$

\section{Conclusions}

\subsection{Implications for Theory and Future Research}

Notwithstanding a few key works [21,28,43,45-47], research that linked exterior sourcing with complementary technology, has offered a lukewarm treatment to radicalness of innovations. The framework introduced in this paper and its subsequent findings open the gates for deeper investigation and enhance prior research on exterior sourcing and technology complementariness [21,23, $24,32,48-51]$ by linking it with radicalness.

The findings from our paper are crucial if firms decide to look outside their own industry to seek technologies that are distinct from their current portfolio. Selection capabilities of partners, especially when technologies are "markedly" different from firm's existing ones are crucial not only to bring radical innovations, but also for long term performance $[21,52]$, and strategic renewal $[21,53]$. Should the firm decide to crossover industrial boundaries to bring complementary technologies into its portfolio, its success depends on its ability to balance the information overload while not losing grasp on the distinct technology. Our findings suggest that if a firm has too many links outside its focal industry to tap innovations, the success of radicalness is contingent on getting access to highly distinct technology. If the technology is drastically different the firms may need to develop and routinize information filters and focus on certain type of information, while disregarding others [27]. If a firm wants to develop innovations that are radically different from its own offering, structural integration with entities of different industries can be considered as a viable method, which is a consideration for future research. In this context, our findings contribute to the understanding that if with lower instances of links outside its focal industry a firm can get its arms around the distinct technology it will be more cost effective than if they have too many links outside the industry. In addition, if the technology is not too distinct, then the exterior sourcing will only pose as a high integration cost.

This study also extends our understanding of knowledge transfer through integration of complementary knowledge and technologies, especially absorptive capacity and relative absorptive capacity [38,54]. Research on relative absorptive suggests that a firm's ability to learn from its partner is positively affected by similarity in their knowledge bases and structures. Our paper echoes the concern put forth by Makri et al. (2010), that the construct of relative absorptive capacity should be expanded to include complementarity of firm's knowledge bases.

\subsection{Implications for Practice}

To be able to come up with radical innovations, managers are not only expected to grasp new technologies, comprehend fresh knowledge, but also deal with information overload arising from different industry, which often is frustrating. At the firm level, the top management should carefully assess the costs of creating networks outside its focal industry whose integration might take up so many resources that it may not be cost-effec- 
tive to retain the network. Assessment of distinctness of technology and potential market value arising from the resultant radical innovation is fundamental before plunging into forging alliances with extraterrestrial industries. Commitment towards such networks should be made only when there are enough incentives to get past the frictions and frustrations of dealing with information overload, integration problems, and of comprehending technology that is drastically different from managers' current stock of expertise. Firms could think of creating incentive programs for managers for identifying (a) technologies with future potential and create radical markets, and (b) potential partners outside the industry for getting access to such technologies. Such programs may encourage managers to emerge from their comfort zones with existing technologies and search for complementary knowledge, integrate that within the firm's boundaries, and develop novel products that create superior value for customers $[21,55]$.

\section{References}

[1] C. M. Christensen, and J. L. Bower, "Customer Power, Strategic Investment, and the Failure of Leading Firms," Strategic Management Journal, Vol. 17, No. 3, 1996, pp. 197-218.

doi:10.1002/(SICI)1097-0266(199603)17:3<197::AID-S MJ804>3.0.CO;2-U

[2] W. Mitchell, "Whether and When? Probability and Timing of Incumbents' Entry into Emerging Industrial Subfields," Administrative Science Quarterly, Vol. 34, No. 2, 1989, pp. 208-230. doi:10.2307/2989896

[3] C. A. O'Reilly, J. B. Herreld and M. L. Tushman, “Organizational Ambidexterity: IBM and Emerging Business Opportunities," California Management Review, Vol. 51, No. 4, 2009, pp. 74-99.

[4] J. S. Sidhu, H. W. Volberda and H. R. Commandeur, "Exploring Exploration Orientation and Its Determinants: Some Empirical Evidence." Journal of Management Studies, Vol. 41, No. 6, 2004, pp. 913-932. doi:10.1111/j.1467-6486.2004.00460.x

[5] Y. Tsai, J. Y. Lin and L. Kurekova, "Innovative R \& D and Optimal Investment under Uncertainty in High-Tech Industries: An Implication for Emerging Economies," Research Policy, Vol. 38, No. 8, 2009, pp. 1388-1395. doi:10.1016/j.respol.2009.06.006

[6] C. Soosay and P. Hyland, "Exploration and Exploitation: the Interplay between Knowledge and Continuous Innovation," International Journal of Technology Management, Vol. 42, No. 1-2, 2008, pp. 20-35. doi:10.1504/IJTM.2008.018058

[7] P. N. Golder, R. Shacham and D. Mitra, "FindingsInnovations' Origins: When, by Whom, and How Are Radical Innovations Developed?" Marketing Science, Vol. 28, No. 1, 2008, pp. 116-179.

[8] A. Malhotra, A. Majchrzak, R. Carman and V. Lott,
"Radical Innovation without Collocation: A Case Study at Boeing-Rocketdyne," MIS Quarterly, Vol. 25, No. 2, 2001, pp. 229-249. doi:10.2307/3250930

[9] M. Rice, D. Kelley, L. Peters and G. C. O'Connor, "Radical Innovation: Triggering Initiation of Opportunity Recognition and Evaluation." $R \& D$ Management, Vol. 31, No. 4, 2001, pp. 409-420. doi:10.1111/1467-9310.00228

[10] C. A. Di Benedetto, W. S. DeSardo and M. Song, "Strategic Capabilities and Radical Innovation: An Empirical Study in Three Countries," IEEE Transactions on Engineering Management, Vol. 55, No. 3, 2008, pp. 420-433. doi:10.1109/TEM.2008.922645

[11] K. B. Dahlin and D. M. Behrens, "When is an Invention Really Radical? Defining and Measuring Technological Radicalness," Research Policy, Vol. 34, No. 5, 2005, pp. 717-737. doi:10.1016/j.respol.2005.03.009

[12] B. Achilladelis, A. Schwarzkopf and M. Cines, "The Dynamics of Technological Innovation: The Case of the Chemical Industry," Research Policy, Vol. 19, No. 1, 1990, pp. 1-34. doi:10.1016/0048-7333(90)90032-2

[13] D. Harhoff, F. Narin, F. M. Scherer and K. Vopel, "Citation Frequency and the Value of Patented Inventions," The Review of Economics and Statistics, Vol. 81, No. 3, 1999, pp. 511-515. doi:10.1162/003465399558265

[14] C. A. O'Reilly and M. L. Tushman, "Ambidextrous Organization," Harvard Business Review, Vol. 82, No. 4, 2004, pp. 71-81.

[15] M. L. Tushman and C. A. O'Reilly, “Ambidextrous Organizations: Managing Evolutionary and Revolutionary Change," California management Review, Vol. 38, No. 4, 1996, pp. 8-30.

[16] M. L. Tushman and C. A. O'Reilly, "Winning through Innovation: A Practical Guide to Leading Organizational Change and Renewal," Harvard Business School Press, Boston, 2002.

[17] D. C. Galunic and K. M. Eisenhardt, "The Evolution of Intracorporate Domains: Divisional Charter Losses in High-Technology, Multidivisional Corporations," Organization Science, Vol. 7, No. 3, 1996, pp. 255-282. doi:10.1287/orsc.7.3.255

[18] D. Leonard-Barton, "Core Capabilities and Core Rigidities: A Paradox in Managing New Product Development," Strategic Management Journal, Vol. 13, No. S1, 1992, pp. 111-125. doi:10.1002/smj.4250131009

[19] M. A. Hitt, R. E. Hoskisson, R. A. Johnson and D. D. Moesel, "The Market for Corporate Control and Firm Innovation," The Academy of Management Journal, Vol. 39, No. 5, 1996, pp. 1084-1119. doi:10.2307/256993

[20] S. Ghoshal, "Global Strategy: An Organizing Framework," Strategic Management Journal, Vol. 8, No. 5, 1987, pp. 425-440.

[21] M. Makri, M. Hitt and P. Lane, "Complementary Technologies, Knowledge Relatedness, and Invention Outcomes in High Technology Mergers and Acquisitions," Strategic Management Journal, Vol. 31, No. 6, 2010, pp. 602-628.

[22] J. G. March, "Exploration and Exploitation in Organiza- 
tional Learning," Organization Science, Vol. 2, No. 1, 1991, pp. 71-87. doi:10.1287/orsc.2.1.71

[23] L. Fleming, "Recombinant Uncertainty in Technological Search," Management Science, Vol. 47, No. 1, 2001, pp. 117-132. doi:10.1287/mnsc.47.1.117.10671

[24] C. Phelps, "A Longitudinal Study of the Influence of Alliance Network Structure and Composition on Firm Exploratory Innovation," Academy of Management Journal, Vol. 53, No. 4, 2010, pp. 890-913. doi:10.5465/AMJ.2010.52814627

[25] R. Katila and G. Ahuja, "Something Old, Something New: A Longitudinal Study of Search Behavior and New Product Introduction," Academy of Management Journal, Vol. 45, No. 6, 2002, pp. 1183-1194. doi: $10.2307 / 3069433$

[26] J. Scott, "Social Network Analysis: A Handbook," Sage, Thousand Oaks, 1991.

[27] Z. Simsek, "Organizational Ambidexterity: Towards a Multilevel Understanding," Journal of Management Studies, Vol. 46, No. 4, 2009, pp. 597-624. doi:10.1111/j.1467-6486.2009.00828.x

[28] G. Ahuja and C. M. Lampert, "Entrepreneurship in the Large Corporation: A Longitudinal Study of How Established Firms Create Breakthrough Inventions," Strategic Management Journal, Vol. 22, No. 6-7, 2001, pp. 521-543. doi:10.1002/smj.176

[29] M. L. Weitzman, "Recombinant Growth," The Quarterly Journal of Economics, Vol. 113, No. 2, 1998, pp. 331-360. doi: $10.1162 / 003355398555595$

[30] J. B. Sorensen and T. E. Stuart, "Aging, Obsolescence, and Organizational Innovation," Administrative Science Quarterly, Vol. 45, No. 1, 2000, pp. 81-112. doi: $10.2307 / 2666980$

[31] D. A. Levinthal and J. G. March, "The Myopia of Learning," Strategic Management Journal, Vol. 14, No. S2, 1993, pp. 95-112. doi:10.1002/smj.4250141009

[32] F. T. Rothaermel, M. A. Hitt and L. A. Jobe, "Balancing Vertical Integration and Strategic Outsourcing: Effects on Product Portfolio, Product Success, and Firm Performance," Strategic Management Journal, Vol. 27, No. 11, 2006, pp. 1033-1056. doi:10.1002/smj.559

[33] B. H. Hall, A. Jaffe and M. Trajtenberg, "Market Value and Patent Citations," The RAND Journal of Economics, Vol. 36, No. 1, 2005, pp. 16-38.

[34] D. M. Decarolis and D. L. Deeds, "The Impact of Stocks and Flows of Organizational Knowledge on Firm Performance: An Empirical Investigation of the Biotechnology Industry," Strategic Management Journal, Vol. 20, No. 10, 1999, pp. 953-968. doi:10.1002/(SICI)1097-0266(199910)20:10<953::AID-S MJ59>3.0.CO;2-3

[35] L. Rosenkopf and A. Nerkar, "Beyond Local Search: Boundary-Spanning, Exploration, and Impact in the Optical Disk Industry," Strategic Management Journal, Vol. 22, No. 4, 2001, pp. 287-306. doi:10.1002/smj.160

[36] P. G. Audia and J. A. Goncalo, "Past Success and Creativity over Time: A Study of Inventors in the Hard Disk Drive Industry," Marketing Management, Vol. 53, No. 1,
2007, pp. 1-15.

[37] R. M. Grant, "Towards a Knowledge-Based Theory of the Firm," Strategic Management Journal, Vol. 17, Winter Special Issue, 1996, pp. 109-122.

[38] P. J. Lane and M. Lubatkin, "Relative Absorptive Capacity and Interorganizational Learning," Strategic Management Journal, Vol. 19, No. 5, 1998, pp. 461-477. doi:10.1002/(SICI)1097-0266(199805)19:5<461::AID-S MJ953>3.0.CO;2-L

[39] B. L. Basberg, "Patents and the Measurement of Technological Change: A Survey of the Literature," Research Policy, Vol. 16, No. 2-4, 1987, pp. 131-141. doi:10.1016/0048-7333(87)90027-8

[40] W. M. Cohen, A. Goto, A. Nagata, R. R. Nelson and J. P. Walsh, "R \& D Spillovers, Patents and the Incentives to Innovate in Japan and the United States," Research Policy, Vol. 31, No. 8-9, 2002, pp. 1349-1367. doi:10.1016/S0048-7333(02)00068-9

[41] P. C. Grindley and D. J. Teece, "Managing Intellectual Capital: Licensing and Cross-Licensing in Semiconductors and Electronics," California Management Review, Vol. 39, No. 2, 1997, pp. 8-41.

[42] R. Katila, "New Product Search over Time: Past Ideas in Their Prime?" Academy of Management Journal, Vol. 45, No. 5, 2002, pp. 995-1010. doi:10.2307/3069326

[43] R. Katila and G. Ahuja, "Something Old, Something New: A Longitudinal Study of Search Behavior and New Product Introduction," Academy of Management Journal, Vol. 45, No. 6, 2005, pp. 1183-1194. doi: $10.2307 / 3069433$

[44] M. E. Sobel, "Asymptotic Confidence Intervals for for Indirect Effects in Structural Equation Models," Sociology Methodology, No. 13, 1982, pp. 290-310.

[45] O. Granstrand and S. Sjölander, "The Acquisition of Technology and Small Firms by Large Firms," Journal of Economic Behavior \& Organization, Vol. 13, No. 3, 1990, pp. 367-386. doi:10.1016/0167-2681(90)90006-Y

[46] G. Ahuja and R. Katila, "Technological Acquisitions and the Innovation Performance of Acquiring Firms: A Longitudinal Study," Strategic Management Journal, Vol. 22, No. 3, 2001, pp. 197-220. doi:10.1002/smj.157

[47] T. J. Gerpott, "Successful Integration of R \& D Functions after Acquisitions: An Exploratory Empirical Study," $R$ \& D Management, Vol. 25, No. 2, 1995, pp. 161-178. doi:10.1111/j.1467-9310.1995.tb00909.x

[48] M. A. Schilling and C. C. Phelps, "Interfirm Collaboration Networks: The Impact of Large-Scale Network Structure on Firm Innovation," Management Science, Vol. 53, No. 7, 2007, pp. 1113-1126. doi: $10.1287 / \mathrm{mnsc} .1060 .0624$

[49] L. Fleming, and O. Sorenson, "Technology as a Complex Adaptive System: Evidence from Patent Data," Research Policy, Vol. 30, No. 7, 2001, pp. 1019-1039. doi:10.1016/S0048-7333(00)00135-9

[50] O. Sorenson and L. Fleming, "Science and the Diffusion of Knowledge," Research Policy, Vol. 33, No. 10, 2004, pp. 1615-1634. doi:10.1016/j.respol.2004.09.008

[51] O. Sorenson, J. W. Rivkin and L. Fleming, "Complexity, 
Networks and Knowledge Flow," Research Policy, Vol. 35, No. 7, 2006, pp. 994-1017.

doi:10.1016/j.respol.2006.05.002

[52] L. Capron and W. Mitchell, "Selection Capability: How Capability Gaps and Internal Social Frictions Affect Internal and External Strategic Renewal," Organization Science, Vol. 20, No. 2, 2009, pp. 294-312. doi: $10.1287 /$ orsc. 1070.0328

[53] R. Agarwal and C. E. Helfat, "Strategic Renewal of Organizations," Organization Science, Vol. 20, No. 2, 2009, pp. 281-293. doi: 10.1287/orsc. 1090.0423

[54] W. M. Cohen and D. A. Levinthal, "Absorptive Capacity: A New Perspective on Learning and Innovation," Administrative Science Quarterly, Vol. 35, No. 1, 1990, pp. 128-152. doi: $10.2307 / 2393553$

[55] D. G. Sirmon, M. A. Hitt and R. D. Ireland, "Managing Firm Resources in Dynamic Environments to Create Value: Looking Inside the Black Box," Academy of Management Review, Vol. 32, No. 1, 2007, pp. 273-292. doi:10.5465/AMR.2007.23466005 